\title{
Decreased circulating levels of ANGPTL8 in Graves' disease patients
}

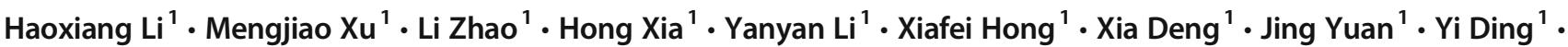 \\ Chang Guo ${ }^{1}$ - Ruirong Pan ${ }^{1}$. Dong Wang ${ }^{1} \cdot$ Jifang Wang ${ }^{1}$ - Wei Yin ${ }^{1} \cdot$ Ling Yang ${ }^{1} \cdot$ Guoyue Yuan ${ }^{1}$
}

Received: 10 October 2018 / Accepted: 30 January 2019 / Published online: 21 March 2019

(C) The Author(s) 2019

\begin{abstract}
Background Angiopoietin-like protein 8 (ANGPTL8), a newly identified hormone, has been recently characterized as a metabolic regulator which can affect energy homeostasis and has interesting potentials as a metabolic disease therapy. However, little is as yet known as to whether circulating ANGPTL8 levels are altered in thyroid dysfunction. This study measured serum ANGPTL8 levels in patients with Graves' disease and explored the correlations between its serum levels and thyroid index in Graves' disease.

Methods The concentration of ANGPTL8 was analyzed in blood samples of 128 well-characterized individuals whose anthropometric parameters, biochemical parameters, and thyroid index were measured. The participants were divided into Graves' disease patients $(n=60)$ and healthy control subjects $(n=68)$. Logistic regression was used to evaluate the relationship between ANGPTL8 and Graves' disease.

Results Serum ANGPTL8 levels were more significantly decreased in Graves' disease patients than in healthy control subjects $(177.67 \pm 135.07$ vs $326.41 \pm 194.72 \mathrm{pg} / \mathrm{mL} ; p<0.001)$. Serum ANGPTL8 was negatively correlated with free triiodothyronine (FT3), free thyroxine (FT4), and thyroid peroxidase antibodies (TPOAb) while being positively correlated with thyrotropin (TSH). Logistic regression analyses demonstrated that serum ANGPTL8 was significantly associated with Graves' disease $(p<0.05)$.

Conclusions Circulating concentrations of ANGPTL8 showed a significant reduction in Graves' disease patients. Thus, it is suggested that thyroid function should be taken into consideration when evaluating the results of ANGPTL8.
\end{abstract}

Keywords ANGPTL8 · Graves' disease

Haoxiang Li and Mengjiao Xu contributed equally to this work.

Ling Yang

lingyang70@163.com

Guoyue Yuan

yuanguoyue@hotmail.com; yuanguoyue08@163.com

Haoxiang Li

nfmlihaoxiang@163.com

Mengjiao Xu

xumengjiaojsdx@163.com

Li Zhao

zhaoli863@163.com

Hong Xia

jsdxxh@163.com

Yanyan Li

lyyface11@sian.com

Xiafei Hong

hxaifei@foxmail.com

Xia Deng

dengxia11@outlook.com
Jing Yuan

ycyj1993@outlook.com

Yi Ding

dingyi007@126.com

Chang Guo

ujsguochang@126.com

Ruirong Pan

ruirong123@163.com

Dong Wang

zjdongdonghao@aliyun.com

Jifang Wang

13646105408@163.com

Wei Yin

yw0511@sohu.com

Department of Endocrinology, Affiliated Hospital of Jiangsu University, 438, Jiefang Road, Zhenjiang 212001, Jiangsu, China 


\section{Introduction}

Angiopoietin-like protein 8 (ANGPTL8), which is also known as TD26 [1], refeeding-induced fat and liver protein (RIFL) [2], lipasin [3], and betatrophin [4], is an atypical member of the ANGPTL family [5]. It is a newly identified protein, composed of 198 amino acids, which is predominantly expressed in liver in humans, while mouse ANGPTL8 is highly enriched in adipose tissue and liver. Over the past few decades, increasing numbers of researchers have focused on the study of ANGPTL8. Recent studies have revealed that ANGPTL8 plays a significant role in several metabolic diseases, in particular, type 2 diabetes mellitus (T2DM) [6-8], obesity [9-11], non-alcoholic fatty liver disease (NAFLD) [12], and polycystic ovary syndrome (PCOS) [13].

Hyperthyroidism is a pathological disorder in which excess thyroid hormone is synthesized and secreted by the thyroid gland. Prevalence of hyperthyroidism is $0.8 \%$ in Europe [14] and $1.3 \%$ in the USA [15]. The most common cause of hyperthyroidism is Graves' disease, followed by toxic nodular goiter. Graves' disease is an autoimmune thyroid disease with such symptoms as weight loss, heat intolerance, tachycardia, and mental disturbances. Recently, many studies have demonstrated that changes in thyroid function are associated with changes in energy metabolism [16-18]. Graves' disease has deleterious metabolic effects on lipid, carbohydrate, and amino acids metabolism $[19,20]$.

Previous research has shown that the levels of circulating hepatocyte- and adipocyte-derived metabolic regulators were altered in patients with thyroid diseases, such as leptin, resistin, adiponectin, and FGF21 [21, 22]. Recently, Han et al. reported that circulating ANGPTL8 was elevated in patients with overt hypothyroidism and subclinical hypothyroidism [23]. However, little is to date known as to whether circulating ANGPTL8 levels are altered in Graves' disease. In this study, we aimed to determine the levels of serum ANGPTL8 in normal control subjects and patients with Graves' disease while further exploring the factors associated with ANGPTL8 levels.

\section{Materials and methods}

\section{Subjects}

A total of 128 subjects were recruited in this study: 68 healthy control subjects and 60 patients diagnosed with Graves' disease who were prepared to receive ${ }^{131}$ I treatment. GD patients were required to discontinue antithyroid drug (ATD) therapy for more than 2 weeks before the treatment. Pretreatment protocol also included obtainment of informed consent, negative pregnancy test, ultrasound measured thyroid or nodule volume, hormonal status, and thyroid scintigraphy. All patients were placed on a lowdose iodine diet 10 days prior to therapy. Individuals with diabetes mellitus, renal disease, nephritic range proteinuria, coronary heart disease, heart failure, peripheral artery disease, cerebrovascular event and malignancy, or other known major diseases were precluded from the study.

\section{Diagnostic criteria}

The diagnosis of Graves' disease was documented by clinical and biochemical evidence of hyperthyroidism, diffused goiter, and the presence of positive thyrotropin (TSH) receptor autoantibody tests, diffusely increased ${ }^{131}$ I (iodine-131) uptake in the thyroid gland, or the presence of exophthalmos.

\section{Anthropometric and biochemical measurements}

Height and weight of all patients were measured to the nearest $0.1 \mathrm{~cm}$ and $0.1 \mathrm{~kg}$, respectively, and BMI was calculated as weight divided by height squared $\left(\mathrm{kg} / \mathrm{m}^{2}\right)$. Blood samples were withdrawn from an antecubital vein after a 10-h overnight fasting. After clotting, blood specimens were separated by centrifugation. Serum samples were subsequently stored at $-80^{\circ} \mathrm{C}$ until immediate analysis of ANGPTL8. Serum glucose levels were determined using the glucose oxidase method. Alanine aminotransferase (ALT), aspartate aminotransferase (AST), gamma glutamyl transpeptidase (GGT), low-density lipoprotein cholesterol (LDL-C), high-density lipoprotein cholesterol (HDL-C), total cholesterol (TC), apolipoprotein A (APOA), apolipoprotein B (APOB), and triglycerides were measured by the kinetic method (Beckman Coulter Inc., Brea, CA, USA). Serum free thyroxine (FT4), free triiodothyronine (FT3), thyrotropin (TSH), thyroid peroxidase antibody (TPOAb), thyroglobulin ( Tg), antithyroglobulin antibody (TgAb), and TSH receptor autoantibody (TRAb) were tested with a chemiluminescence immunoassay (Beckman Coulter Inc., Brea, CA, USA). The radio iodine uptake (RAIU) value was obtained 2, 6 , and $24 \mathrm{~h}$ after an oral tracer dose (about $1850 \mathrm{kBq}$ ) of ${ }^{131} \mathrm{I}$ through a nuclear multifunctional instrument (MN6110XTThyroid function instrument). Thyroidal ${ }^{131} \mathrm{I}$ uptake was calculated according to the following equation: RAIU $(\%)=($ neck counts - background counts $) \times 100 /$ (standard counts - background counts).

\section{Measurement of ANGPTL8}

Serum levels of ANGPTL8 were determined using a commercially available human ELISA Kit (catalog no. E11644h; Wuhan Eiaab Science, Wuhan, China) with an intra-assay coefficient of variation (CV) of $\leq 4.8 \%$ and an inter-assay $\mathrm{CV}$ of $\leq 7.2 \%$. A calibration curve was constructed by plotting 
Table 1 Clinical and biochemical characteristics

\begin{tabular}{|c|c|c|c|}
\hline & Control & Graves' disease & $p$ \\
\hline Age $(\text { year })^{\mathrm{a}}$ & $44.43 \pm 13.39$ & $41.97 \pm 13.1$ & 0.297 \\
\hline $\operatorname{Sex}(F / M)^{b}$ & $68(36 / 32)$ & $60(41 / 19)$ & 0.076 \\
\hline BMI $(\mathrm{kg} / \mathrm{m} 2)^{\mathrm{a}}$ & $21.88(19.93-23.1)$ & $21.03(19.72-22.58)$ & 0.115 \\
\hline $\mathrm{SBP}(\mathrm{mmHg})^{\mathrm{a}}$ & $120.32 \pm 13.83$ & $123.06 \pm 12.19$ & 0.265 \\
\hline $\mathrm{DBP}(\mathrm{mmHg})^{\mathrm{a}}$ & $75.53 \pm 10.83$ & $72.48 \pm 7.88$ & 0.090 \\
\hline Pulse pressure $(\mathrm{mmHg})^{\mathrm{a}}$ & $44.79 \pm 10.03$ & $50.57 \pm 10.84$ & $0.003 *$ \\
\hline $\mathrm{FPG}(\mathrm{mmol} / \mathrm{L})^{\mathrm{a}}$ & $5.11 \pm 0.41$ & $5.12 \pm 0.44$ & 0.987 \\
\hline GGT $(\mathrm{U} / \mathrm{L})^{\mathrm{a}}$ & $16.3(13-22.78)$ & $25.15(17.6-40.78)$ & $<0.001 *$ \\
\hline $\operatorname{ALT}(\mathrm{U} / \mathrm{L})^{\mathrm{a}}$ & $12.65(10-21.23)$ & $28.55(19.68-45.93)$ & $<0.001 *$ \\
\hline $\operatorname{AST}(\mathrm{U} / \mathrm{L})^{\mathrm{a}}$ & $1.17(1.08-1.23)$ & $19.3(13.7-29.1)$ & $<0.001 *$ \\
\hline Triglyceride $(\mathrm{mmol} / \mathrm{L})$ & $0.96 \pm 0.28$ & $1.13 \pm 0.35$ & $0.004 *$ \\
\hline $\mathrm{TC}(\mathrm{mmol} / \mathrm{L})^{\mathrm{a}}$ & $4.35 \pm 0.44$ & $3.35 \pm 0.62$ & $<0.001 *$ \\
\hline $\mathrm{HDL}-\mathrm{C}(\mathrm{mmol} / \mathrm{L})^{\mathrm{a}}$ & $1.37 \pm 0.26$ & $1.11 \pm 0.25$ & $<0.001 *$ \\
\hline LDL-C $(\mathrm{mmol} / \mathrm{L})^{\mathrm{a}}$ & $2.24 \pm 0.33$ & $1.58 \pm 0.47$ & $<0.001 *$ \\
\hline $\operatorname{APOA}(\mathrm{g} / \mathrm{L})^{\mathrm{a}}$ & $1.11(1.02-1.17)$ & $1.11(1-1.24)$ & 0.921 \\
\hline $\operatorname{APOB}(\mathrm{g} / \mathrm{L})^{\mathrm{c}}$ & $0.88(0.78-0.93)$ & $0.68(0.58-0.78)$ & $<0.001 *$ \\
\hline FT3 $(\mathrm{pmol} / \mathrm{L})^{\mathrm{c}}$ & $5.2(4.29-5.67)$ & $18.25(11.22-27.51)$ & $<0.001 *$ \\
\hline FT4 $(\mathrm{pmol} / \mathrm{L})^{\mathrm{c}}$ & $12.56(10.96-16.37)$ & $49.2(34.94-65.52)$ & $<0.001 *$ \\
\hline $\mathrm{TSH}(\mathrm{mIU} / \mathrm{L})^{\mathrm{c}}$ & $1.86 \pm 1.09$ & $0.02 \pm 0.04$ & $<0.001 *$ \\
\hline $\operatorname{TgAb}(\mathrm{IU} / \mathrm{mL})^{\mathrm{c}}$ & $0.35(0.1-11.16)$ & $4.85(0.73-69.83)$ & $<0.001 *$ \\
\hline TPOAb $(\mathrm{IU} / \mathrm{mL})^{\mathrm{c}}$ & $1.36(0.83-2.48)$ & $278.8(67.53-821.22)$ & $<0.001 *$ \\
\hline $\operatorname{Tg}(\mathrm{ng} / \mathrm{mL})^{\mathrm{c}}$ & $8.35(4.6-12.49)$ & $18.35(2.13-75.05)$ & $0.007 *$ \\
\hline $\mathrm{TRAb}(\mathrm{IU} / \mathrm{mL})^{\mathrm{a}}$ & - & $26.05(16.9-65.5)$ & - \\
\hline \multicolumn{4}{|l|}{ RAIU $(\%)$} \\
\hline $2 \mathrm{~h}^{\mathrm{a}}$ & - & $46.03 \pm 1.96$ & - \\
\hline $6 \mathrm{~h}^{\mathrm{a}}$ & - & $67.65(54.53-76.18)$ & - \\
\hline $24 \mathrm{~h}^{\mathrm{a}}$ & - & $72.45(64.05-81.65)$ & - \\
\hline ANGPTL8 (pg/mL) & $326.41 \pm 194.72$ & $177.67 \pm 135.07$ & $<0.001 *$ \\
\hline
\end{tabular}

Data are presented as means $\pm \mathrm{SD}, n(\%)$, and median (25th and 75th percentiles). A $p$ value of $<0.05$ was considered significant $(*)$

$F$ female, $M$ male, $B M I$ body mass index, $S B P$ systolic blood pressure, $D B P$ diastolic blood pressure, $F P G$ fasting plasma glucose, $G G T$ gamma glutamyl transpeptidase, $A L T$ alanine aminotransferase, $A S T$ aspartate aminotransferase, $T C$ total cholesterol, $H D L-C$ high-density lipoprotein cholesterol, $L D L-C$ low-density lipoprotein cholesterol, APOA apolipoprotein A, APOB apolipoprotein B, FT3 free triiodothyronine, T4 free thyroxine, TSH thyrotropin, $T g A b$ anti-thyroglobulin antibody, TPOAb thyroid peroxidase antibody, $T g$ thyroglobulin, $T R A b$ TSH receptor

${ }^{a}$ Independent Student's $t$ test was used

${ }^{\mathrm{b}} \chi^{2}$ test was used

${ }^{\mathrm{c}}$ Non-parametric test was used the absorbance values at $450 \mathrm{~nm}$ versus the ANGPTL8 concentrations of the calibrators, by which concentrations of samples were determined.

\section{Statistical analysis}

All statistical analyses were performed using SPSS version 16.0 (SPSS Inc., Chicago, IL, USA). Data were summarized as means \pm standard deviations for normally distributed variables, medians plus percentiles (25th; 75 th) for non-normally distributed variables, and frequencies for categorical variables. For comparisons between case and control subjects, the independent Student's $t$ test was used for normally distributed variables, while the non-parametric test was used for nonnormally distributed variables. Categorical variables were examined by the $x^{2}$ test. Partial correlation coefficients were calculated to evaluate the associations between serum ANGPTL8 and clinical and laboratory measurements. Partial correlation was used to determine the associations after adjusting for the effects of age, sex, and BMI. Binary logistic 


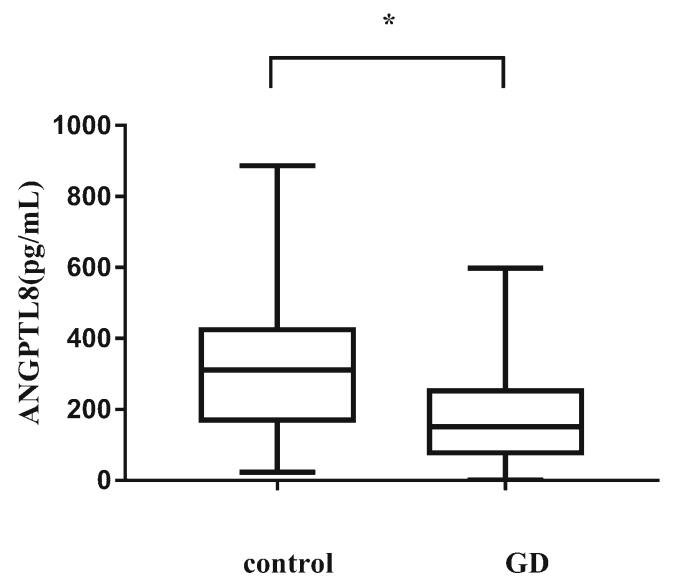

Fig. 1 Serum ANGPTL8 was significantly decreased in the Graves' disease (GD) group compared with the control group. *Statistically significant difference of ANGPTL8 levels between the two groups

regression analyses were performed on the association of ANGPTL8, which were stratified in quartiles to estimate the odds ratio of Graves' disease in each quartile, using the lowest quartile as the reference category. All calculated $p$ values were two-sided and $p$ values $<0.05$ were considered statistically significant.

\section{Results}

\section{Clinical and biochemical characteristics between the two groups}

The clinical and biochemical characteristics of the subgroups studied (control and Graves' disease) are summarized in Table 1 . There were no statistically significant differences between Graves' disease patients and control subjects with respect to age, sex, BMI, SBP, DBP, FPG, and APOA. Compared with those in the control group, pulse pressure, GGT, ALT, AST, triglycerides, FT3, FT4,TgAb, TPOAb, and $\mathrm{Tg}$ in the Graves' disease group were significantly increased $(p<0.01$ or $p<0.05$ ), while TC, HDL-C, LDL-C, APOB, and TSH were significantly decreased $(p<0.01$ or $p<0.05$ ). The average of RAIU value and TRAb is above the normal range in the Graves' disease group.

\section{Serum ANGPTL8 levels}

Serum ANGPTL8 levels between the two groups were $326.41 \pm 194.72 \mathrm{pg} / \mathrm{mL}$ for the control group as opposed to $177.67 \pm 135.07 \mathrm{pg} / \mathrm{mL}$ for the Graves' disease group. Compared with those in the control subjects, the levels of ANGPTL8 in Graves' disease patients were significantly decreased $(p<0.001)$ (Fig. 1).

\section{The prevalence of Graves' disease in the study subjects according to the quartiles of ANGPTL8}

When ANGPTL8 concentrations were stratified in quartiles (Q1, 86.16 $\pm 33.24 \mathrm{pg} / \mathrm{mL}$; Q2, $184.72 \pm 29.29 \mathrm{pg} / \mathrm{mL}$; Q3, $315.59 \pm 43.87 \mathrm{pg} / \mathrm{mL}$; Q4, $564.73 \pm 147.12 \mathrm{pg} / \mathrm{mL}$ ), the association was most pronounced for the fourth quartile, with an OR of 0.111 (95\% CI $0.034-0.357, p<0.001)$ in the age-, BMI-, and sex-adjusted model. This association was already present but less pronounced in the third quartile (age-, BMI-, and sex-adjusted: $\mathrm{OR}=0.273$ [95\% CI 0.091-0.821], $p=$ 0.021) (Fig. 2).

\section{Relationships between serum ANGPTL8 levels and biochemical variables}

Table 2 depicts a correlation analysis between the biochemical variables and ANGPTL8 after adjustment for age, sex, and BMI. ANGPTL8 was negatively correlated with FT3 $(r=-$ $0.302, p=0.001)$, FT4 $(r=-0.386, p<0.001)$, and TPOAb $(r=-0.304, p<0.001)$, but positively correlated with LDL-C $(r=0.302, p=0.006), \mathrm{TC}(r=0.267, p=0.006)$, APOB $(r=$

Fig. 2 Forest plot illustrating the

Odds Ratio $[95 \% \mathrm{Cl}]$ association of ANGPTL8 with Graves' disease and providing data on ANGPTL8 divided into quartiles. ORs and 95\% CLs are shown, and all the data are age-, sex-, and BMI-adjusted

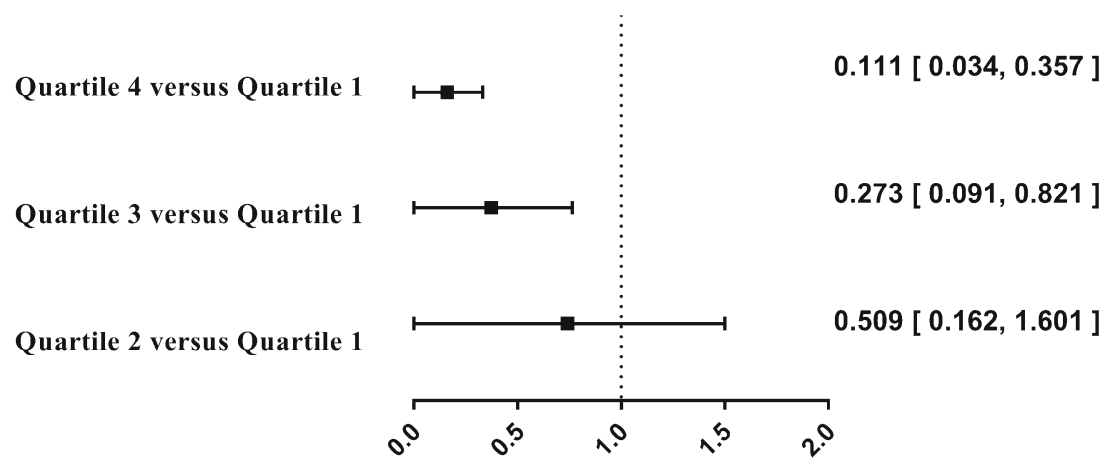

Odds Ratio 
Table 2 Partial correlations analysis of variables associated with circulating ANGPTL8 levels in study subjects

\begin{tabular}{|c|c|c|c|c|}
\hline & \multicolumn{2}{|c|}{ ANGPTL8 } & \multicolumn{2}{|c|}{ ANGPTL8(age, sex, and BMI adjusted) } \\
\hline & $r$ & $p$ & $r$ & $p$ \\
\hline $\mathrm{Age}^{\mathrm{a}}$ & 0.375 & $<0.001 *$ & & \\
\hline $\mathrm{BMI}^{\mathrm{a}}$ & 0.184 & 0.053 & & \\
\hline $\mathrm{SBP}^{\mathrm{a}}$ & 0.203 & $0.029^{*}$ & -0.01 & 0.920 \\
\hline $\mathrm{DBP}^{\mathrm{a}}$ & 0.185 & $0.046^{*}$ & 0.02 & 0.843 \\
\hline Pulse pressure $^{\mathrm{a}}$ & 0.081 & 0.390 & -0.028 & 0.776 \\
\hline $\mathrm{FPG}^{\mathrm{a}}$ & 0.109 & 0.222 & -0.044 & 0.647 \\
\hline $\mathrm{GGT}^{\mathrm{a}}$ & -0.046 & 0.603 & 0.003 & 0.979 \\
\hline $\mathrm{ALT}^{\mathrm{a}}$ & -0.119 & 0.182 & -0.106 & 0.272 \\
\hline $\mathrm{AST}^{\mathrm{a}}$ & -0.056 & 0.533 & -0.069 & 0.476 \\
\hline Triglyceride $^{\mathrm{a}}$ & 0.095 & 0.290 & 0.014 & 0.888 \\
\hline $\mathrm{TC}^{\mathrm{a}}$ & 0.333 & $<0.001 *$ & 0.267 & $0.006^{*}$ \\
\hline HDL-C ${ }^{\mathrm{a}}$ & 0.064 & 0.478 & 0.177 & 0.069 \\
\hline LDL-C $^{\mathrm{a}}$ & 0.32 & $0.001^{*}$ & 0.302 & $0.006^{*}$ \\
\hline $\mathrm{APOA}^{\mathrm{a}}$ & 0.05 & 0.578 & 0.117 & 0.232 \\
\hline $\mathrm{APOB}^{\mathrm{b}}$ & 0.451 & $<0.001 *$ & 0.246 & $0.011 *$ \\
\hline FT3 $^{\mathrm{b}}$ & -0.323 & $0.001 *$ & -0.198 & $0.039^{*}$ \\
\hline $\mathrm{FT}^{\mathrm{b}}$ & -0.386 & $<0.001 *$ & -0.281 & $0.003 *$ \\
\hline $\mathrm{TSH}^{\mathrm{b}}$ & 0.324 & $<0.001 *$ & 0.195 & $0.043^{*}$ \\
\hline $\operatorname{TgAb}^{\mathrm{b}}$ & -0.196 & $0.027 *$ & -0.095 & 0.325 \\
\hline $\mathrm{TPOAb}^{\mathrm{b}}$ & -0.304 & $<0.001 *$ & -0.282 & $0.003 *$ \\
\hline $\mathrm{Tg}^{\mathrm{b}}$ & 0.085 & 0.342 & -0.127 & 0.189 \\
\hline
\end{tabular}

A $p$ value of $<0.05$ was considered significant $(*)$

$B M I$ body mass index, $S B P$ systolic blood pressure, $D B P$ diastolic blood pressure, $F P G$ fasting plasma glucose, $G G T$ gamma glutamyl transpeptidase, $A L T$ alanine aminotransferase, $A S T$ aspartate aminotransferase, $T C$ total cholesterol, $H D L-C$ high-density lipoprotein cholesterol, $L D L-C$ low-density lipoprotein cholesterol, $A P O A$ apolipoprotein A, $A P O B$ apolipoprotein B, FT3 free triiodothyronine, FT4 free thyroxine, $T S H$ thyrotropin, $T g A b$ anti-thyroglobulin antibody, TPOA $b$ thyroid peroxidase antibody, $T g$ thyroglobulin, $T R A b$ TSH receptor autoantibody

${ }^{a}$ Pearson's correlation analysis was used

${ }^{\mathrm{b}}$ Spearman's correlation analysis was used
$0.246, p=0.011)$, and TSH $(r=0.324, p<0.001)$. It was also shown that ANGPTL8 had no correlation with SBP, DBP, pulse pressure, FPG, triglycerides, HDL-C, TgAb, Tg, TRAb, and RAIU.

\section{Discussion}

In this study, we have demonstrated for the first time, to our knowledge, that serum ANGPTL8 concentrations were significantly decreased in Graves' disease patients compared with the control subjects. Our data showed that ANGPTL8 was negatively correlated with FT3, FT4, and TPOAb, but positively correlated with TSH. Furthermore, the trend in the presence of Graves' disease was more apparent in the lower serum ANGPTL8 quartile group. Recently, Han et al. reported that ANGPTL8 was increased in patients with overt and subclinical hypothyroidism. In that study, a total of 122 subjects were recruited, including patients with overt hypothyroidism $(n=31)$, subclinical hypothyroidism $(n=30)$, isolated TPOAb positivity $(n=30)$, and healthy controls $(n=31)$, according to thyroid function. Furthermore, they observed that ANGPTL8 was negatively correlated with FT4 $(r=-$ $0.212, p=0.02)$, and FT3 $(r=-0.225, p=0.01)$, but positively correlated with TSH $(r=0.438, p<0.001)$ [23]. Tseng et al. evaluated gene expression changes in T3stimulated cells by DNA microarray analysis with the aim of identifying the genes in liver cells regulated by T3. In that study, however, they observed that the stimulation of FT3 led to upregulation of both mRNA and protein levels of ANGPTL8, which was dependent on the thyroid hormone receptor that binds to the ANGPTL8 upstream element [24]. Further studies are needed to elucidate the mechanisms underlying decreased ANGPTL8 levels in Graves' disease patients. 
In our research, we observed that serum ANGPTL8 concentrations were positively correlated with LDL-C, TC, and APOB, which suggested that ANGPTL8 might also be involved in lipid metabolism. A study performed by Fenzl et al. found that serum ANGPTL8 is significantly associated with TC, LDL-C, and APOB in patients with long-duration T2DM [25]. In a study of 559 subjects aged 14-28 years, Fu et al. observed that participants in the highest quartile of ANGPTL8 levels had the highest levels of TC, triglycerides, and LDL-C [26]. Sequence variants of the ANGPTL8 gene have been correlated with decreased HDL and LDL levels in Hispanic and African Americans [5]. This observation is in line with the positive correlation between ANGPTL8 and LDL-C in Graves' disease participants reported here. Another study has shown that ANGPTL8 is a stressresponse protein that regulates fat metabolism by suppressing adipose triglyceride lipase (ATGL) expression, revealing a mechanistic connection between ANGPTL8 and lipid homeostasis in mammalian cells [27]. It has been widely accepted that thyroid hormone has major effects on the metabolism of lipids [28-30]. Elevated levels of thyroid hormone in hyperthyroidism are associated with increased clearance of lipolysis and cholesterol. Investigations need to be carried out into whether the low levels of LDL-C, TC, and APOB in Graves' disease might be mediated by decreased ANGPTL8 release. Given that ANGPTL8 is attracting ever more attention among researchers in the field of metabolic diseases, we recommend that further studies be conducted to elucidate the role of ANGPTL8 in the development of Graves' disease.

The limitations of our study also require comment. Firstly, this study is limited by its cross-sectional design; thus, only associations (not causation) between serum ANGPTL8 and thyroid function could be addressed. Secondly, we divided subjects into groups according to thyroid function prior to random selection, which may have caused selection bias. Thirdly, serum ANGPTL8 levels may be affected by possible and variable acute stress experienced by the individual subjects. Due to these limitations, more large-scale populationbased prospective studies are warranted.

In summary, our results indicate that circulating ANGPTL8 concentrations were significantly decreased in Graves' disease patients. Moreover, serum ANGPTL8 was negatively correlated with FT3, FT4, and TPOAb, but positively correlated with TSH, TC, LDL-C, and APOB. ANGPTL8 may hence play a role in the pathogenesis of Graves' disease.

Author contributions Haoxiang Li, Mengjiao Xu, Li Zhao, Hong Xia, Yanyan Li, Xiafei Hong, Xia Deng, Jing Yuan, Yi Ding, Chang Guo, Ruirong Pan, Dong Wang, Jifang Wang, Wei Yin, Ling Yang, and Guoyue Yuan participated in the study design; and Chang Guo performed ELISA. Haoxiang Li, Mengjiao Xu, Li Zhao, and Hong Xia participated in the study design, analyzed the data, and wrote, reviewed, and edited the manuscript. Yanyan Li, Xiafei Hong, Xia Deng, Jing Yuan, Yi Ding, Chang Guo, Ruirong Pan, Dong Wang, Jifang Wang, and Wei Yin provided serum samples and contributed to discussions of data interpretation. All authors reviewed and edited the manuscript. Guoyue Yuan and Ling Yang are the guarantors of this work and, as such, had full access to all the data in the study and take responsibility for the integrity of the data and the accuracy of the data analysis.

Funding information This study was supported in part by grants from the National Natural Science Foundation of China $(81870548,81570721)$, the Natural Science Foundation of Jiangsu Province, China (BK20151331), the High Caliber Medical Personnel Foundation of Jiangsu Province (LGY2016053), the Six Talent Peaks Project in Jiangsu Province (2015WSN-006), the Scientific Research Projects of Jiangsu Health and Family Planning Commission (Y2018109) and the Social Development Project of Jiangsu Province (BE2018692).

\section{Compliance with ethical standards}

The study was approved by the Clinical Research Ethics Committee, Affiliated Hospital of Jiangsu University. Informed consent was obtained from participants.

Conflict of interest The authors declare that they have no conflict of interest.

Open Access This article is distributed under the terms of the Creative Commons Attribution 4.0 International License (http:// creativecommons.org/licenses/by/4.0/), which permits unrestricted use, distribution, and reproduction in any medium, provided you give appropriate credit to the original author(s) and the source, provide a link to the Creative Commons license, and indicate if changes were made.

\section{References}

1. Dong XY, Pang XW, Yu ST, Su YR, Wang HC, Yin YH, Wang YD, Chen WF (2004) Identification of genes differentially expressed in human hepatocellular carcinoma by a modified suppression subtractive hybridization method. Int J Cancer 112:239-248

2. Santulli G (2014) Angiopoietin-like proteins: a comprehensive look. Front Endocrinol 5:4

3. Zhang R (2012) Lipasin, a novel nutritionally-regulated liverenriched factor that regulates serum triglyceride levels. Biochem Biophys Res Commun 424:786-792

4. Yi P, Park JS, Melton DA (2013) Betatrophin: a hormone that controls pancreatic beta cell proliferation. Cell 153:747-758

5. Quagliarini F, Wang Y, Kozlitina J, Grishin NV, Hyde R, Boerwinkle E, Valenzuela DM, Murphy AJ, Cohen JC, Hobbs HH (2012) Atypical angiopoietin-like protein that regulates ANGPTL3. Proc Natl Acad Sci U S A 109:19751-19756

6. Hu H, Sun W, Yu S, Hong X, Qian W, Tang B, Wang D, Yang L, Wang J, Mao C, Zhou L, Yuan G (2014) Increased circulating levels of betatrophin in newly diagnosed type 2 diabetic patients. Diabetes Care 37:2718-2722

7. Chen X, Lu P, He W, Zhang J, Liu L, Yang Y, Liu Z, Xie J, Shao S, Du T, Su X, Zhou X, Hu S, Yuan G, Zhang M, Zhang H, Liu L, Wang D, Yu X (2015) Circulating betatrophin levels are increased in patients with type 2 diabetes and associated with insulin resistance. J Clin Endocrinol Metab 100:E096-E100

8. Yi M, Chen RP, Yang R, Guo XF, Zhang JC, Chen H (2015) Betatrophin acts as a diagnostic biomarker in type 2 diabetes mellitus and is negatively associated with HDL-cholesterol. Int J Endocrinol 2015:479157 
9. Wu S, Gao H, Ma Y, Fu L, Zhang C, Luo X (2016) Characterisation of betatrophin concentrations in childhood and adolescent obesity and insulin resistance. Pediatr Diabetes 17:53-60

10. Barja-Fernandez S, Folgueira C, Seoane LM, Casanueva FF, Dieguez C, Castelao C, Aguera Z, Banos R, Botella C, de la Torre R, Fernandea-Garcia JC, Fernandez-Real JM, Fruhbeck G, Gomez-Ambrosi J, Jimenez-Murcia TFI, Estivill X, FernandezAranda F, Nogueiras R (2015) Circulating betatrophin levels are increased in anorexia and decreased in morbidly obese women. $\mathrm{J}$ Clin Endocrinol Metab 100:E1188-E1196

11. Tuhan H, Abaci A, Anik A, Catli G, Kume T, Calan OG, Acar S, Bober E (2016) Circulating betatrophin concentration is negatively correlated with insulin resistance in obese children and adolescents. Diabetes Res Clin Pract 114:37-42

12. Lee YH, Lee SG, Lee CJ, Kim SH, Song YM, Yoon MR, Jeon BH, Lee JH, Lee BW, Kang ES, Lee HC, Cha BS (2016) Association between betatrophin/ANGPTL8 and non-alcoholic fatty liver disease: animal and human studies. Sci Rep 6:24013

13. Sahin Ersoy G, Altun Ensari T, Vatansever D, Emirdar V, Cevik O (2017) Novel adipokines WISP1 and betatrophin in PCOS: relationship to $\mathrm{AMH}$ levels, atherogenic and metabolic profile. Gynecol Endocrinol 33:119-123

14. Garmendia Madariaga A, Santos Palacios S, Guillen-Grima F, Galofre JC (2014) The incidence and prevalence of thyroid dysfunction in Europe: a meta-analysis. J Clin Endocrinol Metab 99: 923-931

15. Hollowell JG, Staehling NW, Flanders WD, Hannon WH, Gunter EW, Spencer CA, Braverman LE (2002) Serum TSH, T(4), and thyroid antibodies in the United States population (1988 to 1994): National Health and Nutrition Examination Survey (NHANES III). J Clin Endocrinol Metab 87:489-499

16. Silva JE (2003) The thermogenic effect of thyroid hormone and its clinical implications. Ann Intern Med 139:205-213

17. Pontikides N, Krassas GE (2007) Basic endocrine products of adipose tissue in states of thyroid dysfunction. Thyroid 17:421-431

18. Knudsen N, Laurberg P, Rasmussen LB, Bülow I, Perrild H, Ovesen L, Jørgensen T (2005) Small differences in thyroid function may be important for body mass index and the occurrence of obesity in the population. J Clin Endocrinol Metab 90:4019-4024

19. Duntas LH, Biondi B (2013) The interconnections between obesity, thyroid function, and autoimmunity: the multifold role of leptin. Thyroid 23:646-653

20. Han C, He X, Xia X, Li Y, Shi X, Shan Z, Teng W (2015) Subclinical hypothyroidism and type 2 diabetes: a systematic review and meta-analysis. PLoS One 10:e0135233
21. Lee Y, Park YJ, Ahn HY, Lim JA, Park KU, Choi SH, Park DJ, Oh BC, Jang HC, Yi KH (2013) Plasma FGF21 levels are increased in patients with hypothyroidism independently of lipid profile. Endocr J 60:977-983

22. Oge A, Bayraktar F, Saygili F, Guney E, Demir S (2005) TSH influences serum leptin levels independent of thyroid hormones in hypothyroid and hyperthyroid patients. Endocr J 52:213-217

23. Han C, Xia X, Liu A, Zhang X, Zhou M, Xiong C, Liu X, Sun J, Shi X, Shan Z, Teng W (2016) Circulating betatrophin is increased in patients with overt and subclinical hypothyroidism. Biomed Res Int 2016:5090852

24. Tseng YH, Ke PY, Liao CJ, Wu SM, Chi HC, Tsai CY, Chen CY, Lin YH, Lin KH (2014) Chromosome 19 open reading frame 80 is upregulated by thyroid hormone and modulates autophagy and lipid metabolism. Autophagy 10:20-31

25. Fenzl A, Itariu BK, Kosi L, Fritzer-Szekeres M, KautzkyWiller A, Stulnig TM, Kiefer FW (2014) Circulating betatrophin correlates with atherogenic lipid profiles but not with glucose and insulin levels in insulin-resistant individuals. Diabetologia 57:1204-1208

26. Fu J, Hou C, Li L, Feng D, Li G, Li M, Li C, Gao S, Li M (2016) Vitamin D modifies the associations between circulating betatrophin and cardiometabolic risk factors among youths at risk for metabolic syndrome. Cardiovasc Diabetol 15:142

27. Zhang Y, Li S, Donelan W, Xie C, Wang H, Wu Q, Purich DL, Reeves WH, Tang D, Yang LJ (2016) Angiopoietin-like protein 8 (betatrophin) is a stress-response protein that down-regulates expression of adipocyte triglyceride lipase. Biochim Biophys Acta 1861:130-137

28. Abdel-Gayoum AA (2014) Dyslipidemia and serum mineral profiles in patients with thyroid disorders. Saudi Med J 35:1469

29. Risal P, Maharjan B, Koju R, Makaju R, Gautam M (2010) Variation of total serum cholesterol among the patient with thyroid dysfunction. Kathmandu Univ Med J 8:265-268

30. Lai Y, Wang J, Jiang F, Wang B, Chen Y, Li M, Liu H, Li C, Xue H, Li N, Yu J, Shi L, Bai X, Hou X, Zhu L, Lu L, Wang S, Xing Q, Teng X, Teng W, Shan Z (2011) The relationship between serum thyrotropin and components of metabolic syndrome. Endocr J 58: 23-30

Publisher's note Springer Nature remains neutral with regard to jurisdictional claims in published maps and institutional affiliations. 